\title{
Atypical Fracture With Use of Ibandronate and the Role of Bone Scintigraphy on its Early Diagnosis
}

\author{
Josivan Gomes de Limaa, b, c, Flavia da Costa Fernandes ${ }^{\mathrm{a}}$, Alexandre Barbosa Camara de Souza ${ }^{\mathrm{a}}$, \\ Antonio Correia dos Santos Junior ${ }^{\mathrm{a}}$, Bartira Miridan X. C. R. Reboucas ${ }^{\mathrm{a}, \mathrm{b}}$, \\ Natalia Nobrega de Lima ${ }^{a}$, Lucia Helena Coelho Nobrega ${ }^{a, b}$, \\ Andre Gustavo P. Sousa ${ }^{\mathrm{a}, \mathrm{b}}$, Deciara Jacome Torres Medeiros de Mesquita ${ }^{\mathrm{a}}$
}

\begin{abstract}
We report a case of a 49 year-old woman with osteoporosis in treatment with sodium ibandronate $150 \mathrm{mg}$ per week for 5 years that presented leg and knees pain, causing her to stop physical activities. There were no alterations on the physical examination or on plain radiography of legs. A bone scintigraphy with technetium-99m $(99 \mathrm{mTc})$ methylene diphosphonate showed a high uptake on the medial third of both femurs and 20 days later, while walking on the street, she fractured her right femur on the position listed above. Even though it is uncommon, bisphosphonates can predispose atypical fractures after a long time of use. It is difficult, though, to predict which patients are going to develop it. This case brings up the question whether bone scintigraphy could be useful as an exam to the early diagnose of atypical fractures on patients using bisphosphonates for a long period of time.
\end{abstract}

Keywords: Ibandronate; Bone scintigraphy; Atypical fracture; Early diagnosis

\section{Introduction}

Osteoporosis is a major health issue worldwide with an estimated prevalence of 200 million. In the European Union, the number of osteoporotic fractures was estimated at 3.79 million [1]. One of the best treatment options so far is bisphosphonates, they are widely used on the treatment of osteoporosis and prevention of bone fractures. Its mechanism is based on the reduction of bone remodeling by causing osteoclasts apoptosis $[2,3]$. However, due to this particularity,

\footnotetext{
Manuscript accepted for publication June 12, 2013

${ }^{a}$ HUOL-Hospital Universitário Onofre Lopes, UFRN, Departamento de Medicina Clinica, Natal, RN, Brazil

${ }^{\mathrm{b}} \mathrm{CEN}-\mathrm{Centro}$ de Endocrinologia de Natal, Natal, RN, Brazil

${ }^{\mathrm{c}}$ Corresponding author: Josivan Gomes de Lima,

Email: josivanlima@gmail.com
}

doi: http://dx.doi.org/10.4021/jem166w they might allow a phenomenon called as "frozen skeleton", and therefore, cause the accumulation of microcracks over time, leading to fatigue fractures (also called insufficiency fractures). Even though the absolute risk is low, the treatment with a bisphosphonate for more than 5 years is associated with an increased risk of subtrochanteric or femoral shaft fractures [4]. In a cohort study comparing women with osteoporosis who had taken bisphosphonates and those who hadn't, it was found an age-adjusted relative risk of atypical fracture of 47.3 (95\% confidence interval(CI), 25.6 to 87.3 ) and an increase in absolute risk of 5 cases per 10,000 patientyears $(95 \% \mathrm{CI}, 4$ to 7$)$ on the patients using the mentioned medication [5].

Usually the first imaging exam used to diagnose these fractures is a plain film; however, some fractures are too difficult to detect with this exam, being discovered only by a very experienced professional. For this reason, other exams such the bone scintigraphy or a magnetic resonance (MRI) could be useful.

\section{Case Report}

IDPO, female, aged 49, under treatment for osteoporosis, hypothyroidism and hypercholesterolemia. She was submitted to a bone densitometry in 2006 that showed osteoporosis of the lumbar spine (T-score $=-2,6 \mathrm{DP}$ ) and osteopenia of the femoral neck (T-score $=-1,2 \mathrm{DP})$. The patient practices exercise regularly, BMI $=25 \mathrm{~kg} / \mathrm{m}^{2}$ and has no history of smoking. She was on levothyroxine $125 \mathrm{mcg} /$ day and had $\mathrm{TSH}=2.1 \mathrm{mIU} / \mathrm{mL}$ and began sodium ibandronate $(150 \mathrm{mg} /$ month), calcium carbonate $1000 \mathrm{mg}$ /day and cholecalciferol $400 \mathrm{UI} /$ day.

On the following year, there was no significant improvement on the densitometry and the calcium and cholecalciferol doses were increased (1600 mg/day and $800 \mathrm{UI} /$ day). She had a slight improvement in densitometry on 2008 (Table 1). In 2009, there was an insufficient $25-\mathrm{OH}$ vitamin D (27.5 ng/ $\mathrm{ml}$ ), and the daily dose of cholecalciferol was increased to $1600 \mathrm{UI} /$ day, which normalized the deficit (25-OH-vitamina D $36.7 \mathrm{ng} / \mathrm{ml}$ ). In 2010, the patient complained of pain in the legs and knees, causing her to stop physical activity. On that 


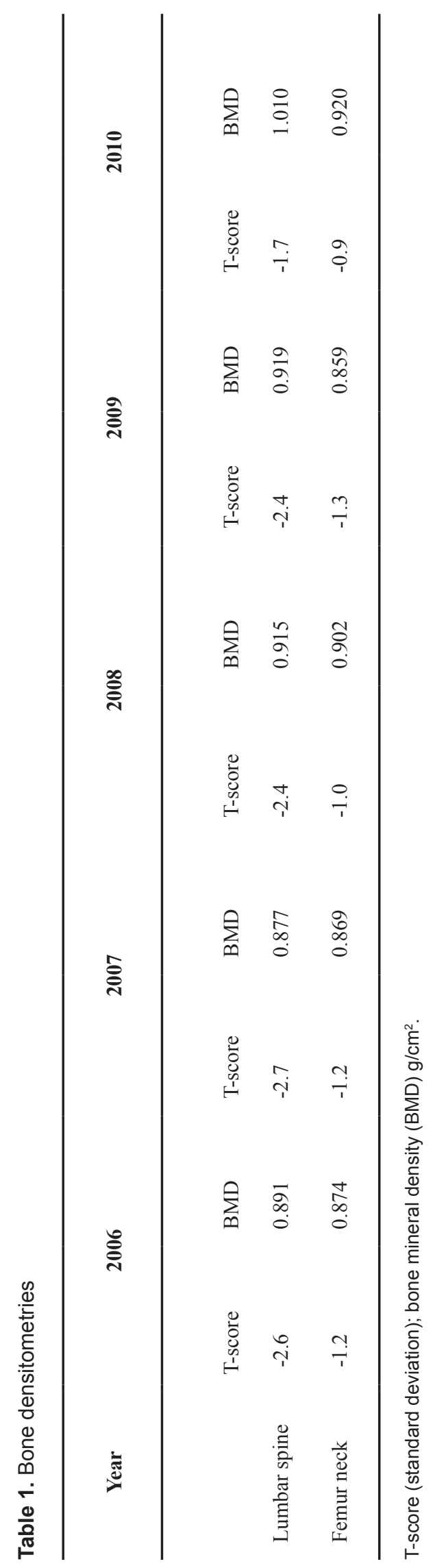

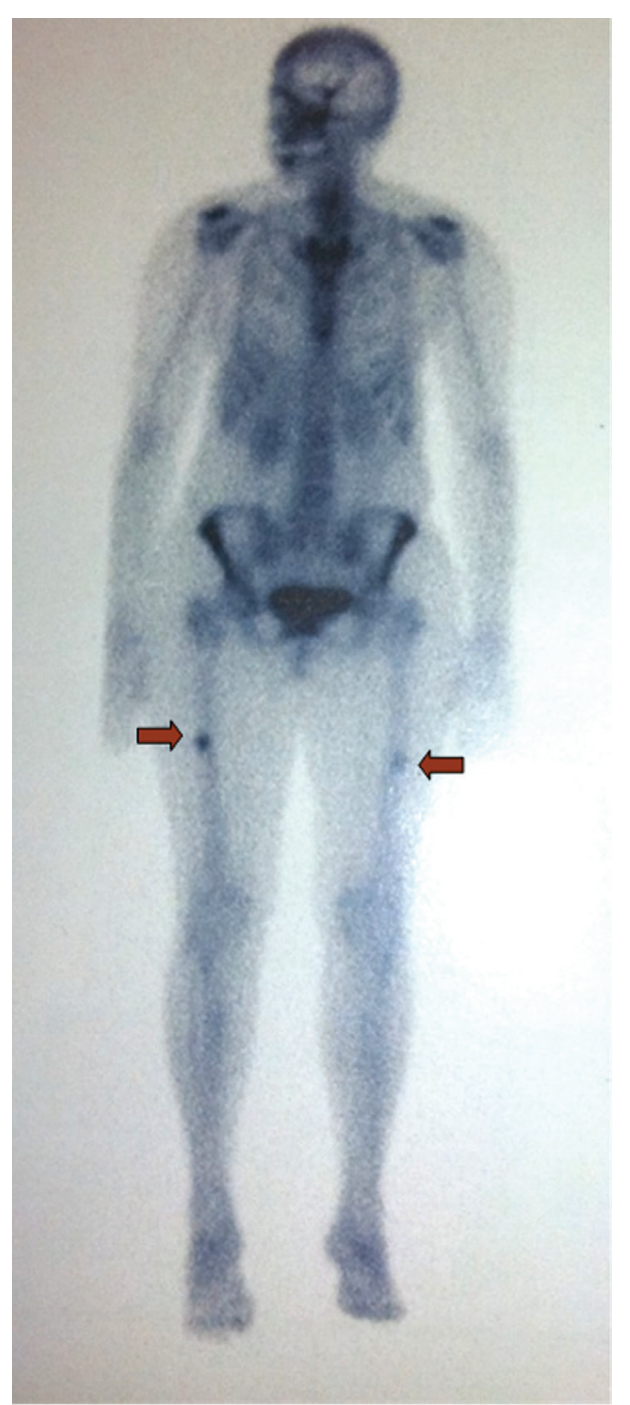

Figure 1. Bone scan revealing, through intense hypercaptation, localization of future fracture.

year, bone densitometry showed significant improvement of the mineral bone density on lumbar spine and femur neck.

She returned in 2011, with 5 years of use ibandronate and worsening of symptoms on the knees and legs. Physical examination showed no motor deficit. Laboratory tests (calcium, phosphorus, alkaline phosphatase, aldolase, 24 hour urinary calcium) were normal. Electromyography, radiography and thoracic MRI of the spine showed no significant changes. Bone scintigraphy (Fig. 1) showed a hypercaptation in the posterior part of the 7th and 8th right ribs, on the posterior part of the 10th and 11th left ribs and on the middle third of both femurs.

Twenty days after consultation, walking down the street, the patient fractured her right femur. She had no gastrointestinal complaints, denied any use of corticosteroids or proton pump inhibitors. She had used fluoxetine during a brief period. The serum protein electrophoresis was normal. Radiog- 


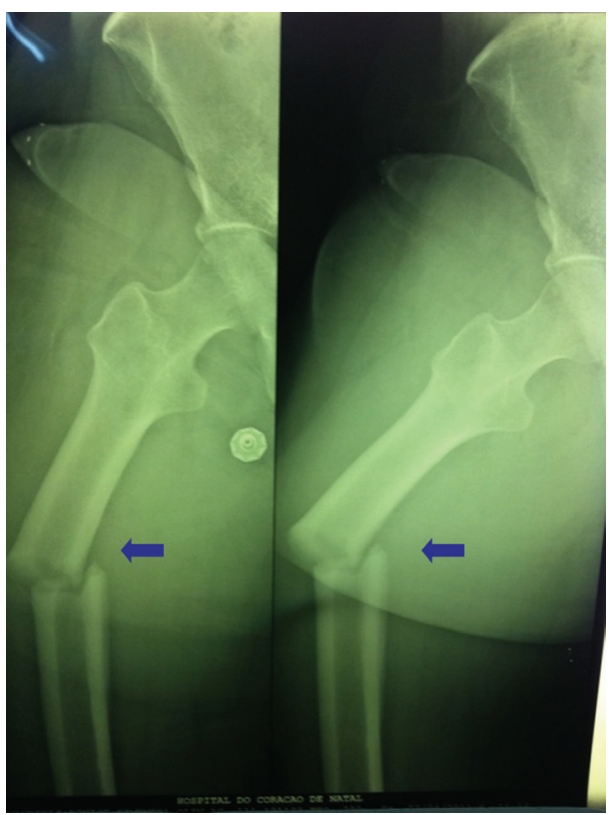

Figure 2. Atypical femur fracture on bone radiography.

raphy of the right leg (Fig. 2) showed a complete transverse fracture of the middle third of the proximal femur with misalignment between the bone ends, in the same altered place of the scintigraphy. Mammography and Pap smear were normal. Ibandronate was suspended and she was started on strontium ranelate $2 \mathrm{~g}$.

\section{Discussion}

Even though the prevalence of bisphosphonate-related femoral atypical fractures is small, it is necessary to be prepared to early diagnose before they can evolve into a complete fracture. There is no possibility to predict which patients are going to develop an insufficiency fracture after using the bisphosphonate, and it can be a challenge to discover the fracture before it can be clinically manifested.

The diagnosis is based on imaging exams such as plain radiography, computed tomography, magnetic resonance imaging (MRI) or bone scintigraphy (BS). On the plain film their appearance are often characterized by a liner radiolucency running perpendicularly to tractional forces and situated through thickening of the lateral cortex, usually on proximal diaphyseal location [6]. They can also develop as a complete fracture with misalignment of both cortical ends of the bone. Usually the plain film is the first imaging examina- tion performed. However, the sensitivity is not too trustworthy, so if it turns out to be negative, then MRI or BS are indicated to further evaluate the clinical finding. MRI can show very early and minor bone distress, which can be sometimes confusing when trying to differentiate physiological and pathological bone stress.

The BS can show changes preceding the plain film by up to a few weeks because it can detect more easily the increased osteoblastic activity associated with a stress fracture, and some authors defend its use as the ideal exam to discover other types of fractures that are difficult to diagnose, such as occult scaphoid stress fractures. On such cases it has been shown that it has sensitivity of $100 \%$ and specificity of $98 \%$ compared with only $64 \%$ on the plain radiography.

On this case report, the initial approach of the patient's complaint with the plain film was insufficient: this imaging exam was not able to detect the stress fractures that were already developing on the patient's femurs. The BS, on the other hand, was able to detect the inflammatory process on its early stages. Perhaps it could be useful to use the BS as a screening exam to patients on bisphosphonates for a long period and with a clinical hypothesis of atypical fracture.

\section{References}

1. Reginster JY, Burlet N. Osteoporosis: a still increasing prevalence. Bone. 2006;38(2 Suppl 1):S4-9.

2. Goh SK, Yang KY, Koh JS, Wong MK, Chua SY, Chua DT, Howe TS. Subtrochanteric insufficiency fractures in patients on alendronate therapy: a caution. J Bone Joint Surg Br. 2007;89(3):349-353.

3. Kwek EB, Goh SK, Koh JS, Png MA, Howe TS. An emerging pattern of subtrochanteric stress fractures: a long-term complication of alendronate therapy? Injury. 2008;39(2):224-231.

4. Park-Wyllie LY, Mamdani MM, Juurlink DN, Hawker GA, Gunraj N, Austin PC, Whelan DB, et al. Bisphosphonate use and the risk of subtrochanteric or femoral shaft fractures in older women. JAMA. 2011;305(8):783789.

5. Schilcher J, Michaelsson K, Aspenberg P. Bisphosphonate use and atypical fractures of the femoral shaft. $\mathrm{N}$ Engl J Med. 2011;364(18):1728-1737.

6. Porrino JA, Jr., Kohl CA, Taljanovic M, Rogers LF. Diagnosis of proximal femoral insufficiency fractures in patients receiving bisphosphonate therapy. AJR Am J Roentgenol. 2010;194(4):1061-1064. 